Table 1

Mean Risky Shitt for Each Item and Condition

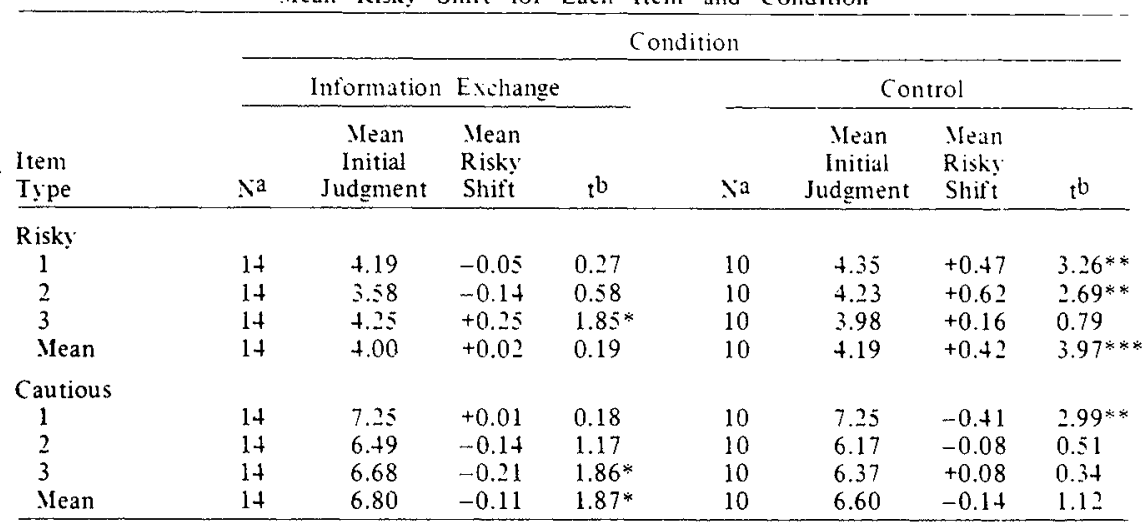

a Vumber of groups: $b$ To establish if shifts differ from zero

${ }^{*} p<.10$. no.tailed: ${ }^{* *} p<.05$. nio-tailed: $* * * p<.01$. mo-tailed

of variance was done on group shift scores to evaluate the predicted interaction between item type (a within-Ss variable) and condition (a between-Ss variable). Besides a significant item type main effect $(\mathrm{F}=13.18, \mathrm{df}=1 / 22, \mathrm{p}<.01)$, there was a significant Item Type by Condition interaction effect $(\mathrm{F}=6.10, \mathrm{df}=1 / 22$, $\mathrm{p}<.05$ ) which was opposite to prediction. The obtained differences in shifts on risky and cautious items were greater for the control than for the information exchange condition (Table 1).

In risky shift research it is customary to use $t$ tests to determine if mean shifts differ from zero (Table 1). According to the information-exchange hypothesis, there should be a cautious shift on cautious items and a risky shift on risky items in the information exchange condition but not in the control condition. Only limited support was found for the hypothesis. In the information condition there were supporting trends $(p<.10)$ on one risky item, one cautious item, and on the mean of cautious items. Moreover, in the control condition there were unexpected significant shifts $(\mathrm{p}<.05$ or better) on two risky items, the mean of risky items, and one cautious item.

\section{DISCUSSION}

The information-exchange hypothesis concerning shift was directly tested by providing minimal sufficient conditions for exchange of information concerning others' initial judgments. The data replicated the previous Wallach \& Kogan (1965) finding of no significant shift when information about others' initial judgments is provided. Mere knowledge of others' judgments may play a role in discussion conditions where Ss may feel freer to forsake their initial commitment than in the present setting. However, it is more likely that discussion produces shifts by other processes, such as providing new

reasons for moving toward the cultural value of an item (Brown, 1965).

The finding of significant shifts in the control condition replicated a previous finding (Myers, Murdoch, \& Smith, in press). It reiterates the suggestion that investigators use group data as a baseline for evaluating the additional effects of experimental treatments involving groups. REFERENCES

BATESON, N. Familiarization, group discussion. and risk-taking. Journal of Experimental Social Psychology, 1966, 2, 119-129.

BROWN, R. Social psychology. New York: The Free Press, 1965.

KOGAN, N., \& WALLACH, M. A. Risk taking: $A$ study in cognition and personality. New York: Holt, Rinehart, \& Winston, 1964.

KOGAN, N.. \& WALLACH, M. A. Risk taking as

\section{E. DOROSH, J. E. TONG, and D. R. BOISSONNEAULT, University of Guelph, Guelph, Ontario, Canada}

Two signal-detection procedures were used to parcel out the effects of white noise and instructions with a two-flash discrimination task. Neither condition influenced the sensitivity scores of either model. Variations in instructions changed the criterion and threshold measures. High correlation coefficients were obtained for the corresponding scores of the two signal-detection analyses.

Recent papers indicate a relationship between physiological measures of "arousal" and two-flash fusion threshold (TFF), or show changes in TFF under manipulated "arousal" conditions or differences in TFF between groups defined according to "arousal" hypotheses

\title{
White noise, instructions, and two-flash fusion with two signal-detection procedures
}

a function of the situation, the perion. and the rroup. In . Vew directions in psichologn /II. ew lork: Holt. Rinchart * Winton. 1967. Pp. $111-278$.

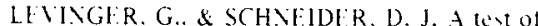
the "risk is a value" hypothesis. Joumal of Personality \& Souial Psychology. 1969. 11. 165-169.

MYERS. D. G. Enhancement of initial risk taking tendencies in social situations. Lnpublished doctoral dissertation. Lniversity of Iowa. 1967.

MYERS. D. G.. IILRDOCH. P.. \& SMITH. G. I. Responsibility diffusion and drive enhancement effects on risky shift. Journal of Personality. in press.

NORDHOY, F. Group interaction in decision-making under risk. Cnpublished Ifaster's thesis. Massachusetts Institute of Technology. 1962

STONER. J. A. F. Risk! and cautious shifts in group decisions: The intluence of widely held values. Journal of Experimental Social Psychology. 1968, 4. 442-459.

TEGER, A. 1.. \& PRLITT. D. G. Components of group risk taking. Journal of Experimental Social Psychology. 1967. 3. 189-205.

VIDMAR, N. Group composition and the risky shift. Journal of Experimental Social Psychology. in press.

WALLACH. M. A.. \& KOGAN, ‥ The roles of information. discussion. and consensus in group risk taking. Journal of Fxperinental Social Psychology. 1965.1. 1-19.

WALLACH. M. A.. \& WING. C. W.. JR. Is risk a value? Journal of Perionality \& Social Psychology. 1968. 9.101-106.

\section{NOTF}

1. This research was supported by a junior faculty research grant to the first author from the Public Health Service and the Liniversity of lowa, a grant (MH-15999-01) to the second author from the National Institute of Mental Health, and an NDEA Title IV fellowship to the third author.
(Venables, 1963a; Rose, 1966. Horn \& Venables, 1964; Hieatt \& Tong, 1969). The psychophysical method used can influence greatly the threshold score (Pearson \& Tong, 1968), and there are indications that forced-choice techniques are essential in that derived scores produce significant results whereas other psychophysical scores fail to reach significance. Clark (1966) has shown that signal-detection procedures are important in perceptual studies with pathological groups. A signal-detection analysis can determine whether differences are the result of criterion placement or sensitivity. Gruzelier \& Corballis (in press) manipulated drugs and instructions in a TFF experiment designed for a signal-detection analysis. The model chosen (Treisman \& Watts, 1966) differs from traditional signal-detection theory (Green $\&$ Swets, 1966), being based on the method of constant stimuli, and appears to 
offer certain practical advantages for TFF work. To date no empirical study comparing the two signal-detection models in respect to TFF has been reported. The following experiment was designed to test both models and make a direct comparison of scores.

\section{HYPOTHESES}

(1) Concurrent white noise will produce decreases in Sensitivity scores with the TFF procedure, without affecting Criterion scores. (2) The variation in instructions to $S$ from Facilitating through Neutral to Inhibiting will increase Criterion scores without affecting the Sensitivity scores. (3) Both white noise and instructions will influence the Treisman and Watts Threshold measure.

\section{APPARATUS}

A dark room with the display screen was used for $S$, and a control room for $E$. The TFF apparatus has been described elsewhere (Pearson \& Tong, 1968) and is similar to that of other workers. A clinical audiometer was used to supply $40 \mathrm{~dB}$ of white noise binaurally through headphones. Under $0-\mathrm{dB}$ noise conditions, the headphones were left on.

\section{PROCEDURE}

Each $\mathrm{S}$ was given six 50-min sessions, each on a different day. The six sessions took the form of a 3 by 2 design with repeated measures for each $S$. The three levels of instruction and two levels of white noise produced six conditions which were arranged in a Latin square.

All sessions took the same form: a $5-\mathrm{min}$ dark adaptation period, then a 15 -min training period, then a 5 -min break, then a 25 -min test given in seven blocks of flash presentation, each followed by a 30 -sec break. Headphones were in place throughout. Each block of the test comprised 40 flash presentations, $50 \%$ of which were randomly distributed single flashes ( $0 \mathrm{IFI}$ ), the remaining presentations being paired flashes of IFI values 20, 30, $40,50,60,70$, or $80 \mathrm{msec}$. Hence, of the total 280 test presentations 140 were 0 IFI and 20 at each $10-\mathrm{msec}$ IFI from 20-80 msec.

$\mathrm{S}$ was given standard general instructions and then one of three special instructions according to the session (for him): (1) Facilitating-" "Report two flashes if there was the slightest suggestion two flashes occurred." (2) Neutral-"Report two flashes if you are fairly certain that there were two flashes, but try not to guess." (3) Inhibiting--"Report two flashes only if you are absolutely certain that two flashes occurred. Do not guess."

\section{ANALYSES}

For the Swets analyses, the false alarm rate was determined by taking the percentage of incorrect ("two") responses to the single flashes (O IFI) for each $S$ under each condition to determine the coordinate along the axis of a $1 \times 1$ graph. The $Y$ coordinate was determined from the correct ("two") responses to the double flashes. The $d^{\prime}$ scores (sensitivity) were obtained from the table of $\mathrm{d}^{\prime}$ in Swets (1964). Criterion levels were obtained by estimating the slope of the ROC curves at the appropriate coordinates. For the Treisman and $W$ atts analyses, the probability $p(T)$ of reporting two flashes at each IFI was calculated for each $S$ under each of the six conditions. Each $p(T)$ was then expressed as a probit score (Finney, 1952). After eliminating any $\mathrm{p}(\mathrm{T})$ of 0 or 1 straight lines representing the least square linear regressions of probits on IFIs were calculated for each $S$ under each condition. Threshold, Sensitivity, and Criterion scores were then calculated according to the Treisman and Watts formulae.

\section{RESULTS}

Four 2 by 3 analyses of variance with repeated measures were undertaken for the dependent variables, Sensitivity (Swets), Sensitivity (Treisman \& Watts), Criterion (Swets), and Criterion (Treisman \& Watts). For both Sensitivity measures, neither Instructions nor Noise produced significant effects. The overall mean for Sensitivity (Swets) was 1.88 and for Sensitivity (Treisman \& Watts), 0.054.

Both sets of Criterion measures were increased by the Inhibiting instructions, but Noise carried no consistent effect. The Instructions main effect in the analysis of variance for Criterion (Swets) was significant at the 0.01 level of $p$, but at the .25 level only for Criterion (Treisman \& Watts). A t-test comparison of Criterion (Treisman \& Watts) between Facilitating and Inhibiting conditions was significant $(\mathrm{p}<.01)$. The overall mean for Criterion (S) was 4.76, and Criterion (T \& W) 2.15.

The Threshold scores for the Treisman and Watts model were significantly increased by Instructions, i.e., Facilitating mean 34.28, Neutral 42.41, Inhibiting $42.55 \mathrm{msec}(\mathrm{p}<.025)$. Noise brought no significant change.

Correlation coefficients between the various dependent variables were all significant, as would be expected as they all were derived from the same initial data. The size of $\mathrm{r}$ varied considerably, however, i.e., for $95 \mathrm{df}$, Sensitivity (S) vs Criterion (S) $r=.39 \quad(p<.005)$, vs Sensitivity $(\mathrm{T} \& \mathrm{~W}) \mathrm{r}=.54$, vs Criterion ( $\mathrm{T} \& \mathrm{~W}) .17$ $(\mathrm{p}<.05)$; Criterion (S) vs Sensitivity $(T \& W) .32 \quad(p<.005)$, vs Criterion $(\mathrm{T} \& \mathrm{~W}) .68 ;$ Sensitivity $(\mathrm{T} \& \mathrm{~W})$ vs Criterion $(\mathrm{T} \& \mathrm{~W}) \mathrm{r}=.68$. DISCUSSION

The results indicate that TFF research can usefully employ signal-detection methodology that should resolve questions concerning whether pathological differences in thresholds are the result of sensitivity factors or differences in attitudinal bias between $S$ s or are created by conditions. That $40-\mathrm{dB}$ white noise brought no change in any dependent variable was unexpected from signal-detection theory but in line with Venables's (1963b) finding for TFF with normals. The insignificant trend for a Sensitivity change brought out by the Swets measure only suggests that higher noise levels should be employed. The application of these procedures brought about a lower threshold measure, by nearly $50 \%$, than that usually obtained by other methods. In general, the results support Hypothesis 2, support the Instructions part of Hypothesis 3, and do not support Hypothesis 1. The Swets method appears the more sensitive of the two s.d. methods used.

\section{REFERENCES}

CLARK, W. C. The psyche in psychophysics: A sensory decision theory analysis of the effect of instructions on flicker sensitivity and response bjas. Psychological Bulletin, 1966, 65, 358-366.

FINNEY, D. J. Probit analysis. (2nd ed.) Cambridge: Cambridge University Press, 1952. GREEN, D. B., \& SWETS, J. A. Signal detection theory and psychophysics. New York: Wiley, 1966 .

GRUZELIER, J. H., \& CORBALLIS, M. C. A signal detection analysis of the effects of instructions and drug administration on temporal resolution of paired light flashes. Quarterly Journal of Experimental Psychology, in press.

HIEATT, D. J., \& TONG, J. E. Differences between normals and schizophrenics in activation induced change in two flash fusion threshold. British Journal of Psychiatry, $1969,115,477-478$.

HORN, G., \& VENABLES, P. H. The effect of somaesthetic and acoustic stimuli on the threshold of fusion of paired light flashes in human subjects. Quarterly Journal of Experimental Psychology, 1964, 16, 289-296.

PEARSON, L. A., \& TONG, J. E. Two flash fusion threshold: The influence of age, psychophysical method, instructions, viewing conditions, sex and subject variability. British Journal of Psychology, 1968, 59, 407-414.

ROSE, R. Anxiety and arousal: A study of two flash fusion and skin conductance. Psychonomic Science, 1966, 6, 821-82.

SWETS, J. A. (Ed.), Signal detection and recognition by human observers: Contemporary readings. New York: Wiley, 1964.

TREISMAN, M., \& WATTS, T. R. Relation between signal detectability theory and the traditional procedures for measuring sensory thresholds. Psychological Bulletin, 1966, 66, 438-454.

VENABLES, P. H. The relationship between skin potential and fusion of paired light flashes in schizophrenic and normal subjects. Journal of Psychiatric Research, 1963, 1, 279-287.

VENABLES, P. H. Changes due to noise in the threshold of fusion of paired light flashes in schizophrenics and normals. British Journal of Social Psychology, 1963, 2, 94-99. 